\title{
Overactive bladder, differential diagnosis, and clinical utility of fesoterodine
}

This article was published in the following Dove Press journal:

International Journal of General Medicine

9 November 2012

Number of times this article has been viewed

\section{Jean-Jacques Wyndaele}

Department of Urology, Antwerp University, Antwerp, Belgium
Correspondence: Jean-Jacques Wyndaele Department of Urology, Antwerp University, 10 Wilrijkstraat, 2650 Edegem, Antwerp, Belgium

Tel +32382 I 35II

Fax +32 382। 4479

Email jean-jacques.wyndaele@uza.be

\begin{abstract}
Overactive bladder is a symptom syndrome with urgency, frequency and, in many cases, nocturia. Urge incontinence is not present in all. There is no direct correlation with detrusor overactivity, an objective finding during urodynamic testing where involuntary contractions can be noticed. In the pathophysiology, much more attention has been given to the afferent/sensory arm of the micturition reflex in the last decade. Anatomical and infectious causes have to be diagnosed or ruled out. Diagnosis of overactive bladder is made mostly by history-taking, but other tests can be necessary in specific patients. Treatment consists of behavioral measures, a good explanation of the condition, training, and pelvic floor physiotherapy. Drugs are often used. Until recently, antimuscarinic drugs have been the mainstay of pharmacological therapy. Fesoterodine is a newer antimuscarinic agent which is more pharmacodynamically stable then tolterodine. Fesoterodine has been extensively researched using different dosages and compared with placebo and tolterodine, in different age groups, and under different conditions. Fesoterodine is superior to placebo and to tolterodine in the short term and long term. Its safety is very acceptable.
\end{abstract}

Keywords: overactive bladder, fesoterodine, incontinence, urgency, lower urinary tract

\section{Definitions and epidemiology}

The term overactive bladder has been used for two and a half decades now. Originally it referred to the storage phase of the bladder and was intended to be diagnosed by urodynamic testing. ${ }^{1}$ This is now defined as detrusor overactivity, ie, involuntary contractions of the detrusor muscle that occur while the patient tries to inhibit voiding. A more recent definition was proposed in 2000, ie, the overactive bladder is a medical condition referring to the symptoms of frequency and urgency, with or without urge incontinence, when appearing in the absence of local pathology or metabolic factors that would account for these symptoms. ${ }^{2}$ Incontinence is not a necessary condition for diagnosis, because almost half of those with symptoms of overactive bladder are not incontinent. Lower urinary tract symptoms (LUTS) are prevalent. The European Prospective Investigation into Cancer and Nutrition (EPIC) study ${ }^{3}$ was the first large-scale, multinational, population-based, cross-sectional survey to estimate the prevalence of LUTS using 2002 International Continence Society definitions, with a focus on subtypes of LUTS, overactive bladder, and urinary incontinence. International Continence Society definitions include overactive bladder symptoms of urgency (complaint of a sudden, compelling desire to urinate that is difficult to defer), urge urinary incontinence (involuntary leakage accompanied or immediately preceded by urgency), frequency (complaint of voiding too often during the day, mostly 
considered as $>8$ times per day), and nocturia (waking to void one or more times per night). ${ }^{4}$ The EPIC study, conducted between April and December 2005, in randomly selected men and women $>18$ years of age living in Canada and in different countries of Europe, showed that LUTS are highly prevalent. Further, $64.3 \%$ of the 19,165 respondents reported experiencing at least one symptom arising from the lower urinary tract. Storage LUTS were considerably more prevalent than voiding or post-micturition LUTS in both men and women. The prevalence of overactive bladder was comparable in men $(10.8 \%)$ and women (12.8\%) and increased with age in both genders. Nocturia was the most prevalent symptom in both men (48.6\%) and women (54.5\%).

Two large population-based studies have attempted to evaluate the prevalence of overactive bladder, ie, the SIFO (Swedish Institute for Opinion Surveys) study, which was conducted in six European countries in 1997-1998, ${ }^{5}$ and the NOBLE (National Overactive Bladder Evaluation) study, which was conducted in the US. ${ }^{6}$ These studies had found similar but somewhat higher rates of overactive bladder in men (15.6\% and $16.0 \%$, respectively) and women (17.4\% and $16.9 \%$, respectively). However, these studies were conducted before the introduction of the International Continence Society definitions used in the EPIC study. These prevalence figures would make overactive bladder more prevalent than arterial hypertension. ${ }^{7}$ Recent data have challenged this prevalence figure by studying a representative population and using consistent definitions and exclusions. ${ }^{8}$ This results in a prevalence of $8 \%$, which of course still reflects a challenging health problem.

In the worldwide population $\geq 20$ years of age, it is estimated that 455 million people (11\%) experience symptoms of overactive bladder. The overall number of affected males and females worldwide is expected to increase by $20 \%$ to 546 million by the year 2018 . The number of individuals affected by overactive bladder will also continue to increase in Europe. ${ }^{9,10}$

New evidence from longitudinal studies suggests that overactive bladder may be a progressive syndrome. Malmsten et al undertook a longitudinal population-based survey in men aged 45-103 years in the city of Gothenburg, Sweden. ${ }^{11}$ There was a marked increase in the prevalence of urinary incontinence, overactive bladder, and other LUTS in the same men assessed longitudinally over an 11-year period. Urinary incontinence and overactive bladder had a negative influence on health-related quality of life, and men who developed urinary incontinence or overactive bladder had a greater deterioration in health-related quality of life than men who had no change in their urinary incontinence/overactive bladder status over time. Wennberg et al undertook a longitudinal, population-based survey of urinary incontinence, overactive bladder, and other LUTS in women $\geq 20$ years of age between 1991 and $2007 .{ }^{12}$ There was a marked overall increase in the prevalence of urinary incontinence, overactive bladder, and nocturia in the same women.

In a separate UK study of the natural history of overactive bladder in women $\geq 40$ years of age with a 3-year follow-up, the severity of overactive bladder increased progressively with age, accelerating after the age of 60 years. ${ }^{12}$ Persistent overactive bladder seems to be an underestimated problem after treatment for localized prostate cancer, especially in patients treated with brachytherapy. ${ }^{13}$ In a diabetes center in Taiwan, in which all patients were screened, $22.5 \%$ had overactive bladder, and $48.0 \%$ of those with overactive bladder had incontinence. ${ }^{14}$

Growing evidence is showing a strong link between urinary symptoms in childhood, such as nocturnal enuresis and symptoms of overactive bladder, and overactive bladder in adulthood. ${ }^{15}$ Epidemiological and genetic findings demonstrate a strong link between symptoms of overactive bladder in these two different stages of life. Predisposing factors and behavioral and/or environmental elements may lead to the occurrence of overactive bladder in adults.

\section{Current etiological concepts}

There are several different hypotheses involving neurological deficits in the brain, brainstem, and more peripheral innervation. ${ }^{16} \mathrm{~A}$ major role is given to afferent innervation. ${ }^{17}$ Abnormalities of bladder smooth muscle have been related to detrusor overactivity. Prolonged outflow obstruction could have an influence through structural deformation of the smooth muscle in the bladder, increased production of nerve growth factor, and induced neuronal enlargement. ${ }^{18}$ Obstruction would also lead to partial denervation, inducing denervation supersensitivity ${ }^{19}$ and with possible metabolic effects via the generation of free radicals and lipid peroxidase. ${ }^{20}$

\section{Clinical approach and differential diagnosis}

A physician may suspect a patient to suffer from overactive bladder if the patient consults for urinary urgency, frequency, nocturia, or urgency incontinence, in one combination or another. Overactive bladder syndrome is symptom-based, and thus relates to symptoms. ${ }^{21} \mathrm{~A}$ detailed history is the key.

Patients develop elaborate coping mechanisms to manage and hide their symptoms. Seventy percent of patients with 
overactive bladder have tried at least one nonmedical coping strategy. ${ }^{22}$ Patients often delay visiting the doctor because their symptoms are not severe enough, they are too embarrassed to discuss the problem due to a perceived stigma, or they accept such symptoms as part of ageing. Some fail to acknowledge the symptoms at all. ${ }^{23}$ Moreover, many patients who do visit their physician for this problem are not properly treated. ${ }^{3}$

Symptoms of overactive bladder can occur in many conditions, including anatomical disturbances, neurogenic bladder, urinary infection, diuresis problems, stone disease, and cancer of the lower urinary tract. Therefore, a thorough differential diagnosis is needed to eliminate such causes before labeling the problem as overactive bladder syndrome. Such diagnostic evaluation needs a detailed history, physical examination, urine analysis, and eventually imaging, endoscopy, or more specialist testing.

Urodynamic tests are needed when the probable diagnosis is unclear, if a neurologic problem is suspected, or if therapy has been unsuccessful. Conventional laboratory urodynamics failed to detect an abnormality in $>35 \%$ of patients in the study by van Waalwijk van Doorn. ${ }^{24}$ Ambulatory urodynamic monitoring would seem to detect motor overactivity more easily, but it would seem appropriate to accept that only if pressure rises correspond with the signs and symptoms of overactive bladder, because changes in detrusor pressure can also be detected in many asymptomatic subjects. ${ }^{25}$ Warning signs and symptoms such as pain, hematuria, urinary retention, and neurological signs are not part of overactive bladder syndrome and always warrant further examination.

Evaluation can be done in a standardized manner using a voiding diary and questionnaires. A sensation-related voiding diary seems optimal for evaluating symptom-related problems. $^{26,27}$ The Incontinence Quality of Life, King's Health Questionnaire, and International Prostate Symptom Score are amongst the questionnaires used in overactive bladder syndrome. ${ }^{28}$

\section{Overactive bladder and quality of life}

An overactive bladder has a very negative effect on quality of life. ${ }^{5}$ In most domains (physical functioning, social functioning, vitality, role limitations) patients with overactive bladder syndrome score significantly worse than do agematched controls. Compared with quality of life in patients with diabetes, depression, and hypertension, only depression has a more severe negative impact. ${ }^{29}$

\section{Nondrug treatment}

Research on treatment of overactive bladder syndrome has been the subject of great activity during recent decades, not in the least because of the development of new drugs. The aims of treatment in overactive bladder syndrome have both quantitative and qualitative components. Quantitative treatment is directed towards decreasing episodes of urgency, incontinence, and frequency every 24 hours, and towards increasing the volume voided and urgency-free time. Qualitative treatment aims to reduce the severity of symptoms of overactive bladder and improve quality of life.

Nondrug forms of treatment have been studied, including behavioral therapy, pelvic physiotherapy, electrical stimulation, and biofeedback, along with more invasive treatments, including intravesical treatment, neuromodulation, and surgery. The following is a short summary of these techniques.

Behavioral therapy is one of the best single treatment options available because it has no risk and gives very acceptable results. ${ }^{30}$ It starts with proper education and an explanation of normal lower urinary tract function and the clinical aspects of overactive bladder. When patients understand what actually happens to them, they can better interpret the signs and symptoms. More personal information can be obtained from voiding dairies. Training can start consequently with timed voiding and bladder training, including being attentive and thus perceiving the early signs of an overactive contraction or imminent desire to void, inhibition of this sensation, delayed voiding, and reinforcement of these steps when successful. Fluid management is important, as are lifestyle corrections. The voiding diary can help to set goals, aiming for better control with a reasonable voiding interval and no incontinence. Training for good micturition habits can be useful. Behavioral therapy can be combined with drug intake and pelvic physiotherapy. Psychological help and reassurance are mostly satisfactory. Behavioral therapy is effective, with success rates of $50 \%-80 \%{ }^{30}$

Pelvic physiotherapy consists of several techniques. Exercise has been used to try and stop the development of autonomic contractions by squeezing the pelvic floor muscles. Contraction of the pelvic floor muscles provides reflex inhibition of the detrusor muscle. ${ }^{31}$ The evidence supporting bladder and pelvic floor muscle training is more consistent, and a trend towards combining these therapies to treat overactive bladder appears positive. ${ }^{32}$

Electrical stimulation with vaginal electrodes can reduce the occurrence of symptoms of overactive bladder. ${ }^{33}$ 
Biofeedback has been used to relate directly, in a very successful way, the changes in intravesical pressure (bladder or cystometric biofeedback $)^{34}$ and as a method of pelvic floor training. ${ }^{35}$ Injection of botulinum toxin has been explored and has been recommended for refractory cases by a European discussion panel. ${ }^{36}$ However, dose-dependent development of residual urine has been shown. ${ }^{37}$

Sacral and tibial neuromodulation have become popular because they bridge the gap between conservative treatment and highly invasive options. However, more experience and better studies are needed to evaluate these treatments fully. ${ }^{38,39}$ Some concerns have been raised recently. Although the results have suggested potential benefits, uncertainty exists as to the best techniques and the best stimulation settings. Furthermore, the biological effects have been demonstrated in very heterogeneous patient groups, with soft definitions of success and unclear cure rates..$^{40}$ Bladder augmentation is still advocated for very refractory cases with severe symptoms and a heavy burden on quality of life. ${ }^{41}$

\section{Drug treatment}

Until very recently, muscarinic receptor antagonists had been the most widely used drugs for treating overactive bladder. There is ample clinical evidence that they are effective. Antimuscarinic drugs remain the first-line treatment of overactive bladder and a favorable efficacy-safety ratio can be confirmed..$^{42}$ However, side effects often limit their use, especially dry mouth, constipation, and blurred vision. Oxybutynin has been used for many years, is still the drug of choice in several countries, and has acceptable clinical efficacy. ${ }^{43}$ To limit its side effects, alternative routes of administration have been used, including extended-release oral formulations, the transcutaneous route, intravesical instillation, and stimulation of salivation. ${ }^{44}$

A better understanding of muscarinic receptors and their role in bladder function has lead to the development of tissueselective and subtype-selective antimuscarinic agents with improved tolerability. The role of antimuscarinics in afferent innervation has become clear. ${ }^{45-47}$

Two major evaluations of clinical studies showed that all the antimuscarinics reviewed were more effective than placebo. Efficacy was superior to that of placebo in number of incontinence episodes, number of micturitions per day, volume voided per micturition for fesoterodine (4 mg/8 mg), immediate-release oxybutynin $15 \mathrm{mg}$ three times daily, extended-release propiverine $(20 \mathrm{mg})$, solifenacin $(5 \mathrm{mg} / 10 \mathrm{mg}$ ), and tolterodine (4 mg extendedrelease, $2 \mathrm{mg} / 4 \mathrm{mg}$ immediate-release). The number of urgency episodes per day improved significantly compared with placebo for fesoterodine, propiverine, solifenacin, and tolterodine. ${ }^{48,49}$

Challenges in drug management include the placebo effect. In a systematic review of placebo-controlled, randomized trials in overactive bladder, ${ }^{50}$ statistically significant improvements were found in three patientreported outcomes, ie, incontinence episodes per day, micturition episodes per day, and mean micturition volume from baseline, after placebo in randomized studies of overactive bladder. These findings highlight the role of the brain in the pathophysiology of overactive bladder and the role of additional bladder training conducted as part of clinical trials in overactive bladder.

Adherence and persistence with drug intake for overactive bladder is not good. An evaluation of proportion of days covered, a measure of medication adherence, as an indicator of quality in drug therapy management, across a sample of six chronic therapies found variable but uniformly suboptimal medication use. Adherence with prostaglandin eye drops and overactive bladder medications was lower than with cardiovascular, oral antidiabetic, and oral osteoporosis therapies. $^{51}$

Multiple factors affect patient compliance with drug treatment for overactive bladder. Treatment-related factors include dosing frequency, dose flexibility, mode of administration, adverse events, and inadequate symptom control. Among patient factors are unrealistic expectations of treatment, attitudes to pharmacotherapy, comorbidities, cost/insurance cover, and preferring to treat symptoms on demand..$^{52}$ Expectations about treatment efficacy and side effects are the most important considerations in discontinuing overactive bladder medications for most patients. Interventions to promote realistic expectations about treatment efficacy and side effects might enhance adherence..$^{53}$

\section{Fesoterodine}

Fesoterodine is a nonselective oral antimuscarinic agent. To understand its position among the muscarinic receptor blockers, it is necessary to discuss data on tolterodine. Tolterodine is a competitive antimuscarinic agent currently used for the treatment of overactive bladder. However, the optimal efficacy of tolterodine may be difficult to achieve in some patients. The drug delivers two active moieties, ie, the parent drug (tolterodine) and its equipotent active metabolite (5-hydroxymethyl tolterodine, 5-HMT). These two combined account for the clinical effects of tolterodine. The 5-HMT 
metabolite is formed via the cytochrome P450 (CYP) 2D6 pathway, which is genetically polymorphic, resulting in considerable interpatient variability in the proportion of CYP2D6 moieties.

Fesoterodine was developed to provide stable delivery of 5-HMT, allowing a predictable dose-response relationship, and reducing variability in efficacy and the potential for adverse effects. Fesoterodine has 5-HMT as the sole active moiety without involving CYP2D6-mediated metabolism of tolterodine, thus eliminating dependence on variably expressed CYP2D6 enzymes for drug delivery. ${ }^{54}$ This results in a more predictable pharmacokinetic profile for sustainedrelease fesoterodine than for tolterodine. In a pharmacokinetic study evaluating singe oral doses of fesoterodine tablets $(4,8$, and $12 \mathrm{mg})$, the maximum plasma concentration, area under the concentration-time curve (AUC), and excretion all increased proportionally with dose in both extensive and poor metabolizers of CYP2D6. In addition, fesoterodine has shown consistent pharmacokinetics across a variety of patient groups, with no significant variation in AUC or maximum plasma concentration relating to ethnic group, gender, or age following administration of an $8 \mathrm{mg}$ dose. As a result, fesoterodine has been developed as $4 \mathrm{mg}$ and $8 \mathrm{mg}$ doses to provide additional flexibility and dosing suitable for a wider range of patients. ${ }^{55}$

\section{Efficacy in overactive bladder}

The superiority of fesoterodine $8 \mathrm{mg}$ over extended-release tolterodine $4 \mathrm{mg}$ has been demonstrated in head-to-head, randomized, controlled trials, ${ }^{56,57}$ using a predefined superiority design. Apart from improvement in symptoms, significant improvements were also observed in most patient-reported quality of life measures with fesoterodine $8 \mathrm{mg}$ compared with extended-release tolterodine $4 \mathrm{mg}$ or placebo. Both active treatments were well tolerated, with most adverse events, including dry mouth, being mild-to-moderate in intensity and expected based on the mechanism of action. Superiority was seen as early as 3 weeks after titration of the fesoterodine dose.

\section{Clearly defined dose-response relationship}

The dose-response relationship for fesoterodine in patients with overactive bladder is important for dose titration, helping to determine the dose that is most effective for the patient while minimizing side effects. Longitudinal doseresponse models developed from double-blind, placebocontrolled Phase II and III trial data have demonstrated a consistent dose-response for fesoterodine with regard to bladder diary endpoints. The predicted change was calculated to be -1.2 micturitions for placebo, -1.7 for fesoterodine $4 \mathrm{mg}$, and -2.2 for fesoterodine $8 \mathrm{mg}$ in a typical patient with 11 micturitions per 24 hours at baseline and $-1.1,-1.3$, and -1.4 urge urinary incontinence episodes, respectively, for a typical patient with two urge urinary incontinence episodes per 24 hours at baseline. The increase in mean voided volume was estimated at $9.7 \mathrm{~mL}$ for placebo, with an additional $14.2 \mathrm{~mL}$ and $28.4 \mathrm{~mL}$ increase for fesoterodine $4 \mathrm{mg}$ and $8 \mathrm{mg}$, respectively. Data generated from mathematical modeling support those obtained from post hoc analyses of clinical trials. ${ }^{58}$

Clinical treatment for overactive bladder with antimuscarinic agents such as fesoterodine is most commonly initiated without urodynamic testing. Importantly, the dose-response relationship with fesoterodine was independent of the presence of detrusor overactivity in a randomized, multicenter, placebo-controlled Phase II study. ${ }^{59}$ No significant differences in treatment response between patients with and without detrusor overactivity were seen.

In an open-label, flexible-dose study of adults with overactive bladder who were dissatisfied with previous tolterodine or extended-release tolterodine therapy, $50 \%$ of 516 patients who received at least one dose of fesoterodine opted for dose escalation to fesoterodine $8 \mathrm{mg}$ at week 4 , with significant improvements from baseline to week 12 in symptoms of overactive bladder and health-related quality of life. Four of five patients who responded to the Treatment Satisfaction Questionnaire at week 12 reported that they were "satisfied" with their treatment. ${ }^{60}$

Finally, flexible dosing with fesoterodine was associated with a good safety profile in a 12-week, double-blind, placebocontrolled trial. ${ }^{61}$ At baseline, patients were randomized to fesoterodine $4 \mathrm{mg}$ or placebo once daily; the fesoterodine dose was then increased to $8 \mathrm{mg}$ at 2 weeks in patients requiring such an increase. In total, $63 \%$ and $73 \%$ of fesoterodine $(n=438)$ and placebo $(n=445)$ recipients, respectively, opted for dose escalation. The most common adverse events were dry mouth ( $26 \%$ fesoterodine and $8 \%$ placebo) and constipation (11\% fesoterodine and $6 \%$ placebo). In both groups, $87 \%$ of patients completed the trial; $8 \%$ and $5 \%$ of patients in the fesoterodine and placebo groups, respectively, discontinued treatment because of an adverse event.

A recent evaluation of the efficacy and safety of flexibledose fesoterodine and factors associated with dose escalation in subjects with overactive bladder in a 12-week, open-label study, found that fesoterodine was well tolerated overall 
in 331 adults. $^{62}$ In a recent study, fesoterodine $(4 \mathrm{mg}$ for 4 weeks and $8 \mathrm{mg}$ for 4 weeks) was used in 21 pediatric subjects of mean age 13.2 years and weighing $>25 \mathrm{~kg}$, who had had neurogenic detrusor overactivity for 8 weeks. The results showed steady-state plasma 5-HMT exposures similar to those in adults. The dosage given was well tolerated. ${ }^{63}$

Combined, these data demonstrate that fesoterodine offers the possibility of dose flexibility and titration. The actual recommended starting dosage for fesoterodine is $4 \mathrm{mg}$ once daily, which can be increased to $8 \mathrm{mg}$ once daily depending on patient response. In many patients, starting with $8 \mathrm{mg}$ would seem appropriate.

\section{Effect of comedication on the dose- response curve}

Many patients with overactive bladder, particularly those who are older, suffer from comorbidities such as recurrent falls and fractures, urinary tract and skin infections, and depression. ${ }^{64}$ Therefore, it is important to consider the effect of comedication on the dose-response curve for antimuscarinic agents, including fesoterodine. ${ }^{65}$ Most antimuscarinic agents are metabolized by the liver via the CYP system. Because many other drugs also undergo CYP metabolism, competition for the same metabolic pathway results in a potential for drug-drug interactions.

In a recent study, a single dose of fesoterodine $8 \mathrm{mg}$ was well tolerated when administered alone or with fluconazole. The observed increase in 5-HMT exposure was within the inherent variability of 5-HMT pharmacokinetics, so adjustment of fesoterodine is not warranted when coadministered with a moderate CYP3A4 inhibitor, provided it is not also a transport inhibitor. ${ }^{66}$ The pharmacokinetics and pharmacodynamics of warfarin $25 \mathrm{mg}$ in healthy adults were unaffected by fesoterodine $8 \mathrm{mg}$. Concomitant administration of fesoterodine and warfarin was well tolerated. ${ }^{67}$

Drug pharmacokinetics can be affected by impairment of liver or renal function. In patients with moderate impairment of liver function, maximum plasma 5-HMT concentrations and AUC values were approximately twice those of healthy controls following administration of fesoterodine, whereas the terminal half-life was not significantly affected. ${ }^{68}$ In those with mild, moderate, or severe renal impairment, peak plasma 5-HMT concentrations were 1.35-fold, 1.48-fold, and 2.03-fold greater than in healthy individuals in a study of patients with renal function that varied from a glomerular filtration rate of $>80$ to $<30 \mathrm{~mL}$ per minute; similar findings were also obtained for AUC values. ${ }^{69}$ Fesoterodine can be prescribed for patients with mild to moderate renal or mild hepatic impairment, and the dose can be increased cautiously to $8 \mathrm{mg}$ in patients who require additional efficacy. Patients with moderate hepatic impairment can be prescribed the $4 \mathrm{mg}$ dose of fesoterodine.

An evaluation of flexible-dose fesoterodine versus placebo in men with persistent symptoms of overactive bladder despite receiving $\alpha$-blocker treatment showed good tolerability and significantly greater improvement in frequency and bothersome symptoms compared with placebo, but not in urge episodes or other secondary endpoints at week $12 .^{70}$

\section{Long-term safety with fesoterodine}

Data from a 2-year open-label extension following an initial 12-week double-blind study demonstrated that fesoterodine has a good safety profile, is associated with sustained improvements in symptoms of overactive bladder and health-related quality of life, and has high rates of treatment satisfaction..$^{71}$ During openlabel treatment, all patients received fesoterodine $8 \mathrm{mg}$ for an initial 4 weeks, after which they could elect for dose reduction to $4 \mathrm{mg}$ or remain on $8 \mathrm{mg}$. Of the 417 patients enrolled in the open-label extension study, $61 \%$ continued fesoterodine treatment for $\geq 24$ months and $71 \%$ maintained the $8 \mathrm{mg}$ dose throughout treatment. There were no unexpected safety concerns, and $\geq 88 \%$ of patients rated treatment tolerability as at least "good" throughout the study. Consistent with the short-term studies, dry mouth was the most common treatmentemergent adverse event (34\%) during the open-label study, and resulted in discontinuation of $2 \%$ of patients. Treatment satisfaction was high ( $\geq 84 \%$ ) throughout the study.

Cognitive function in 18 elderly patients with overactive bladder has been studied in a $4-8 \mathrm{mg}$ evaluation versus placebo. ${ }^{72}$ No statistically significant effects versus placebo were found for any cognitive function parameter assessed, including memory. Fesoterodine was not associated with QTc prolongation or any other electrocardiographic abnormalities at therapeutic or supratherapeutic doses in a parallel-group study of fesoterodine $4 \mathrm{mg}, 28 \mathrm{mg}$, placebo, and moxifloxacin for 3 days. ${ }^{73}$ A recent review of a pooled analysis of two openlabel extension studies showed that long-term fesoterodine administered primarily as $8 \mathrm{mg}$ was well tolerated and associated with sustained improvements in symptoms of overactive bladder, irrespective of age. ${ }^{74}$

\section{Fesoterodine versus other antimuscarinic drugs}

Meta-analyses have been done recently to compare the efficacy and safety of the different antimuscarinic drugs, ie, darifenacin, fesoterodine, transdermal oxybutynin, 
oral oxybutynin, propiverine, solifenacin, tolterodine, and trospium chloride. All available drugs have been shown to be efficacious for the treatment of overactive bladder, and clinically relevant differences between them have not been demonstrated consistently. ${ }^{75,76}$ The various drugs are similar in tolerability, with the exception of more dry mouth and central nervous effects with slow-release oxybutynin $>10 \mathrm{mg} /$ day. ${ }^{77}$ As clearly shown in a recent Cochrane review, ${ }^{78}$ the dosage needs to be taken into account when comparing drugs. This again underlines the importance of flexibility and an individualized approach when prescribing antimuscarinics to patients with overactive bladder. Equally important is to take into account pharmacokinetics, which probably with further research will permit better determination of which drugs are more appropriate for use in specific populations, such as patients with neurological disease or the elderly. ${ }^{79}$

\section{Conclusion}

Overactive bladder is a prevalent symptom syndrome. Different therapeutic modalities exist. Fesoterodine is a newer antimuscarinic with a good efficacy and safety profile in the treatment of this condition.

\section{Disclosure}

The author reports no conflicts of interest in this work.

\section{References}

1. Abrams PH, Blaivas JG, Stanton SL, Andersen JT. Standardization of terminology of lower urinary tract function. Neurourol Urodyn. 1988;7: 403-407.

2. Abrams P, Wein AJ. Introduction: overactive bladder and its treatments. Urology. 2000;55 Suppl A:1-2.

3. Milsom I, Irwin D. A cross-sectional, population-based, multinational study of the prevalence of overactive bladder and lower urinary tract symptoms: results from the EPIC study. Eur Urol Suppl. 2007;6:4-9.

4. Abrams P, Cardozo L, Fall M, et al. Standardisation Sub-committee of the International Continence Society. The standardisation of terminology of lower urinary tract function: report from the Standardisation Sub-committee of the International Continence Society. Neurourol Urodyn. 2002;21:167-178.

5. Milsom I, Abrams P, Cardozo L, Roberts RG, Thüroff J, Wein AJ. How widespread are the symptoms of an overactive bladder and how are they managed? A population-based prevalence study. BJU Int. 2001;87: 760-766.

6. Stewart WF, Van Rooyen JB, Cundiff GW, et al. Prevalence and burden of overactive bladder in the United States. World J Urol. 2003;20:327-336.

7. Tubaro A. Defining overactive bladder: epidemiology and burden of disease. Urology. 2004;64:2-6.

8. Tikkinen KA, Tammela TL, Rissanen AM, Valpas A, Huhtala H, Auvinen A. Is the prevalence of overactive bladder overestimated? A populationbased study in Finland. PLoS One. 2007;2:e195.

9. Donaldson MM, Thompson JR, Matthews RJ, Dallosso HM, McGrother CW. Leicestershire MRC Incontinence Study Group. The natural history of overactive bladder and stress urinary incontinence in older women in the community: a 3-year prospective cohort study. Neurourol Urodyn. 2006;25:709-716.
10. Irwin DE, Kopp ZS, Agatep B, Milsom I, Abrams P. Worldwide prevalence estimates of lower urinary tract symptoms, overactive bladder, urinary incontinence and bladder outlet obstruction. BJU Int. 2011;108:1132-1138.

11. Malmsten UG, Molander U, Peeker R, Irwin DE, Milsom I. Urinary incontinence, overactive bladder, and other lower urinary tract symptoms: a longitudinal population-based survey in men aged 45-103 years. Eur Urol. 2010;58:149-156.

12. Wennberg AL, Molander U, Fall M, Edlund C, Peeker R, Milsom I. A longitudinal population-based survey of urinary incontinence, overactive bladder, and other lower urinary tract symptoms in women. Eur Urol. 2009;55:783-791.

13. Boettcher M, Haselhuhn A, Jakse G, Brehmer B, Kirschner-Hermanns R. Overactive bladder syndrome: an underestimated long-term problem after treatment of patients with localized prostate cancer? BJU Int. 2012;109:1824-1830.

14. Liu RT, Chung MS, Lee WC, et al. Prevalence of overactive bladder and associated risk factors in 1359 patients with type 2 diabetes. Urology. 2011;78:1040-1045

15. Salvatore S, Serati M, Origoni M, Candiani M. Is overactive bladder in children and adults the same condition? ICI-RS 2011. Neurourol Urodyn. 2012;31:349-351.

16. Blaivas JG. The neurophysiology of micturition: a clinical study of 550 patients. J Urol. 1982;127:958-963.

17. Wyndaele JJ, Van Meel TD, De Wachter S. Detrusor overactivity. Does it represent a difference if patients feel the involuntary contractions? J Urol. 2004;172:1915-1918.

18. Steers WD, de Groat WC. Effect of bladder outlet obstruction on micturition reflex pathways in the rat. J Urol. 1988;140:864-871.

19. Brading AF, Turner WH. The unstable bladder: towards a common mechanism. Br J Urol. 1994;17:386-388.

20. Levin RM. Discussion: potential future pharmacological approaches. Urology. 1997:50 Suppl 6A:87-88.

21. Ricci JA, Baggish JS, Hunt TL, et al. Coping strategies and health care-seeking behavior in a US national sample of adults with symptoms suggestive of overactive bladder. Clin Ther. 2001;23:1245-1259.

22. Schabert VF, Bavendam T, Goldberg EL, Trocio JN, Brubaker L. Challenges for managing overactive bladder and guidance for patient support. Am J Manag Care. 2009;15(Suppl 4):S118-S122.

23. Wyndaele JJ. The overactive bladder. BJU Int. 2001;88:135-140.

24. Van waalwijk van Doorn ESC. Ambulatory Urodynamics from Physiological Research to Daily Practice. Thesis. Maastricht, The Netherlands: University of Maastricht: 1993.

25. Wyndaele JJ. Normality of urodynamics studied in healthy volunteers. J Urol. 1999;161:899-902.

26. Naoemova I, De Wachter S, Wuyts FL, Wyndaele JJ. Reliability of the 24-h sensation-related bladder diary in women with urinary incontinence. Int Urogynecol J Pelvic Floor Dysfunct. 2008;19:955-959.

27. Naoemova I, De Wachter S, Wyndaele JJ. Comparison of sensationrelated voiding patterns between continent and incontinent women: a study with a 3-day sensation-related bladder diary (SR-BD). Neurourol Urodyn. 2008;27:511-514.

28. Kim SH, Oh SJ. Comparison of voiding questionnaires between female interstitial cystitis and female idiopathic overactive bladder. Int Neurourol J. 2010;14:86-92.

29. Coyne KS, Sexton CC, Kopp ZS, Ebel-Bitoun C, Milsom I, Chapple C. The impact of overactive bladder on mental health, work productivity and health-related quality of life in the UK and Sweden: results from EpiLUTS. BJU Int. 2011;108:1459-1471.

30. Burgio KL, Goode PS, Johnson TM, et al. Behavioral versus drug treatment for overactive bladder in men: the Male Overactive Bladder Treatment in Veterans (MOTIVE) Trial. J Am Geriatr Soc. 2011;59: 2209-2216.

31. Bo K, Berghmans LCM. Non pharmacological treatments for overactive bladder-pelvic floor exercises. Urology. 2000;55 Suppl 5A:7-11.

32. Milne JL. Behavioral therapies for overactive bladder: making sense of the evidence. J Wound Ostomy Continence Nurs. 2008;35:93-101. 
33. Brubacker L. Electrical stimulation in overactive bladder. Urology. 2000;55 Suppl 5A:17-23.

34. Wyndaele JJ, Hoekx L, Vermandel A. The role of bladder biofeedback in the treatment of children with refractory nocturnal enuresis associated with idiopathic detrusor instability and small bladder capacity. J Urol. 1998;160:858-860.

35. Fall M. Discussion: reactivation of bladder inhibitory reflexes - an underestimated asset in the treatment of overactive bladder. Urology. 2000;55 Suppl 5A:29-30.

36. Apostolidis A, Dasgupta P, Denys P, et al. European Consensus Panel. Recommendations on the use of botulinum toxin in the treatment of lower urinary tract disorders and pelvic floor dysfunctions: a European consensus report. Eur Urol. 2009;55:100-119.

37. Dmochowski R, Chapple C, Nitti VW, et al. Efficacy and safety of onabotulinumtoxinA for idiopathic overactive bladder: a double-blind, placebo controlled, randomized, dose ranging trial. J Urol. 2010;184: 2416-2422.

38. Gajewski JB. Patients with medication-refractory OAB symptoms should be further treated with neuromodulation. Can Urol Assoc J. 2011;5:283-284.

39. Liberman D, Valiquette L. Concerns regarding sacral neuromodulation as a treatment option for medical-refractory overactive bladder. Can Urol Assoc J. 2011;5:285-287.

40. Levin PJ, Wu JM, Kawasaki A, Weidner AC, Amundsen CL. The efficacy of posterior tibial nerve stimulation for the treatment of overactive bladder in women: a systematic review. Int Urogynecol J. March 13, 2012. [Epub ahead of print.]

41. Reyblat P, Ginsberg DA. Augmentation enterocystoplasty in overactive bladder: is there still a role? Curr Urol Rep. 2010;11:432-439.

42. Andersson KE, Chapple CR, Cardozo L, et al. Pharmacological treatment of overactive bladder: report from the International Consultation on Incontinence. Curr Opin Urol. 2009;19:380-394.

43. Diokno A, Lapides J. Oxybutinin: a new drug with analgesic and anticholinergic properties. J Urol. 1972;108:307-309.

44. Madersbacher H, Jilg G. Control of detrusor hyperreflexia by intravesical instillation of oxybutinin hydrochloride. Paraplegia. 1991;29:84-90.

45. De Wachter S, Wyndaele JJ. Intravesical oxybutynin: a local anesthetic effect on bladder C afferents. J Urol. 2003;169:1892-1895.

46. De Laet K, De Wachter S, Wyndaele JJ. Systemic oxybutynin decreases afferent activity of the pelvic nerve of the rat: new insights into the working mechanism of antimuscarinics. Neurourol Urodyn. 2006;25: 156-161.

47. Iijima K, De Wachter S, Wyndaele JJ. Effects of the M3 receptor selective muscarinic antagonist darifenacin on bladder afferent activity of the rat pelvic nerve. Eur Urol. 2007;52:842-847.

48. Chapple CR, Khullar V, Gabriel Z, Muston D, Bitoun CE, Weinstein D. The effects of antimuscarinic treatments in overactive bladder: an update of a systematic review and meta-analysis. Eur Urol. 2008;54: 543-562.

49. Novara G, Galfano A, Secco S, et al. A systematic review and metaanalysis of randomized controlled trials with antimuscarinic drugs for overactive bladder. Eur Urol. 2008;54:740-763.

50. Mangera A, Chapple CR, Kopp ZS, Plested M. The placebo effect in overactive bladder syndrome. Nat Rev Urol. 2011;8:495-503.

51. Yeaw J, Benner JS, Walt JG, Sian S, Smith DB. Comparing adherence and persistence across 6 chronic medication classes. J Manag Care Pharm. 2009;15:728-740.

52. Basra RK, Wagg A, Chapple C, et al. A review of adherence to drug therapy in patients with overactive bladder. BJU Int. 2008;102:774-779.

53. Benner JS, Nichol MB, Rovner ES, et al. Patient-reported reasons for discontinuing overactive bladder medication. BJU Int. 2010;105: $1276-1282$.

54. Malhotra B, Darsey E, Crownover P, Fang J, Glue P. Comparison of pharmacokinetic variability of fesoterodine vs tolterodine extended release in cytochrome P450 2D6 extensive and poor metabolizers. Br J Clin Pharmacol. 2011;72:226-234.
55. Malhotra B, Guan Z, Wood N, Gandelman K. Pharmacokinetic profile of fesoterodine. Int J Clin Pharmacol Ther. 2008;46:556-563.

56. Kaplan SA, Schneider T, Foote JE, Guan Z, Carlsson M, Gong J. Superior efficacy of fesoterodine over tolterodine extended release with rapid onset: a prospective, head-to-head, placebo-controlled trial. BJU Int. 2011;107:1432-1440

57. Herschorn S, Swift S, Guan Z, et al. Comparison of fesoterodine and tolterodine extended release for the treatment of overactive bladder: a head-to-head placebo-controlled trial. BJU Int. 2010;105:58-66.

58. Cardozo L, Khullar V, El-Tahtawy A, Guan Z, Malhotra B, Staskin D. Modeling dose-response relationships of the effects of fesoterodine in patients with overactive bladder. BMC Urol. 2010;19:10-14.

59. Nitti VW, Rovner ES, Bavendam T. Response to fesoterodine in patients with an overactive bladder and urgency urinary incontinence is independent of the urodynamic finding of detrusor overactivity. BJU Int. 2010;105:1268-1275

60. Wyndaele JJ, Goldfischer ER, Morrow JD, et al. Effects of flexibledose fesoterodine on symptoms of overactive bladder and treatment satisfaction: an open-label study. Int J Clin Pract. 2009;63:560-567.

61. Dmochowski RR, Peters KM, Morrow JD, et al. Randomized, doubleblind, placebo-controlled trial of flexible-dose fesoterodine in subjects with overactive bladder. Urology. 2010;75:62-68.

62. Cardozo L, Hall T, Ryan J, et al. Safety and efficacy of flexible-dose fesoterodine in British subjects with overactive bladder: insights into factors associated with dose escalation. Int Urogynecol J. May 11, 2012. [Epub ahead of print.]

63. Malhotra B, Eltahtawy A, Wang EQ, et al. Dose-escalating study of the pharmacokinetics and tolerability of fesoterodine in children with overactive bladder. J Pediatr Urol. 2012;8:336-342.

64. Brown JS, McGhan WF, Chokroverty S. Comorbidities associated with overactive bladder. Am J Manag Care. 2000;6(Suppl 11):S574-S579.

65. MacDiarmid SA. How to choose the initial drug treatment for overactive bladder. Curr Urol Rep. 2007;8:364-369.

66. Malhotra B, Dickins M, Alvey C, et al. Effects of the moderate CYP3A4 inhibitor, fluconazole, on the pharmacokinetics of fesoterodine in healthy subjects. Br J Clin Pharmacol. 2011;72:263-269.

67. Malhotra B, Alvey C, Gong J, Li X, Duczynski G, Gandelman K. Effects of fesoterodine on the pharmacokinetics and pharmacodynamics of warfarin in healthy volunteers. Br J Clin Pharmacol. 2011;72:257-262.

68. Witte LP, Mulder WM, de la Rosette JJ, Michel MC. Muscarinic receptor antagonists for overactive bladder treatment: does one fit all? Curr Opin Urol. 2009;19:13-19.

69. Michel M. Fesoterodine: a novel muscarinic receptor antagonist for the treatment of overactive bladder syndrome. Expert Opin Pharmacother. 2008;9:1787-1796.

70. Kaplan SA, Roehrborn CG, Gong J, Sun F, Guan Z. Add-on fesoterodine for residual storage symptoms suggestive of overactive bladder in men receiving $\alpha$-blocker treatment for lower urinary tract symptoms. BJU Int. 2012;109:1831-1840.

71. Van Kerrebroeck PE, Heesakkers J, Berriman S, Padmanabhan Aiyer L, Carlsson M, Guan Z. Long-term safety, tolerability and efficacy of fesoterodine treatment in subjects with overactive bladder syndrome. Int J Clin Pract. 2010;64:584-593.

72. Kay GG, Maruff P, Scholfield D, et al. Evaluation of cognitive function in healthy older subjects treated with fesoterodine. Postgrad Med. 2012; 124:7-15.

73. Malhotra B, Wood, Sachse R, Gandelman K. Thorough QT study of the effect of fesoterodine on cardiac repolarization. Int J Clin Pharmacol Ther. 2010;45:309-318.

74. Sand PK, Heesakkers J, Kraus SR, Carlsson M, Guan Z, Berriman S. Long-term safety, tolerability and efficacy of fesoterodine in subjects with symptoms of overactive bladder stratified by age: pooled analysis of two open-label extension studies. Drugs Aging. 2012;29:119-131.

75. Schneider T, Michel MC. Anticholinergic treatment of overactive bladder syndrome. Is it all the same? Urologe A. 2009;48:245-249. German. 
76. Shamliyan T, Wyman JF, Ramakrishnan R, Sainfort F, Kane RL. Systematic review: benefits and harms of pharmacologic treatment for urinary incontinence in women. Ann Intern Med. 2012;156: 861-874.

77. Kessler TM, Bachmann LM, Minder C, et al. Adverse event assessment of antimuscarinics for treating overactive bladder: a network metaanalytic approach. PLoS One. 2011;6:e16718.
78. Madhuvrata P, Cody JD, Ellis G, Herbison GP, Hay-Smith EJ. Which anticholinergic drug for symptoms of overactive bladder in adults. Cochrane Database Syst Rev. 2012;1:CD005429.

79. Leone Roberti Maggiore U, Salvatore S, Alessandri F, et al. Pharmacokinetics and toxicity of antimuscarinic drugs for overactive bladder treatment in females. Expert Opin Drug Metab Toxicol. August 8, 2012. [Epub ahead of print.]

\section{Publish your work in this journal}

The International Journal of General Medicine is an international, peer-reviewed open-access journal that focuses on general and internal medicine, pathogenesis, epidemiology, diagnosis, monitoring and treatment protocols. The journal is characterized by the rapid reporting of reviews, original research and clinical studies across all disease areas.

\section{Dovepress}

A key focus is the elucidation of disease processes and management protocols resulting in improved outcomes for the patient. The manuscript management system is completely online and includes a very quick and fair peer-review system. Visit http://www.dovepress.com/ testimonials.php to read real quotes from published authors.

Submit your manuscript here: http://www.dovepress.com/international-journal-of-general-medicine-journal 